\title{
Repeat surgical aortic valve replacement: Don’t stick a fork in it just yet
}

\author{
Kevin L. Greason, MD \\ "The reports of my death have been greatly \\ exaggerated."
}

-Mark Twain ${ }^{1}$

An examination of the repeat operation approach to failed biological aortic valve prosthesis, with a focus on the importance and relevance of new findings to thoracic surgeons, is important because of the increasing use of biological valve prostheses with aortic valve replacement. ${ }^{2,3}$ Biological aortic valve prostheses are of limited durability, and valve failure often necessitates repeat valve operation. ${ }^{4}$

Repeat surgical aortic valve replacement (re-SAVR) is the traditional option for biological aortic valve prosthesis failure. ${ }^{4-6}$ Although effective in treating the valve failure, this option carries with it the pain of operation coupled with the risks of bleeding/blood transfusion, renal failure, stroke, and death, to name a few. ${ }^{4-6}$ Valve-in-valve transcatheter aortic valve replacement (VIV TAVR) is a recent alternative first reported in $2007 .^{7}$ Experience with the transcatheter technique has quickly grown, such that in 2015, the Food and Drug Administration approved the technique in selected patients. ${ }^{8,9}$ A percutaneous option for repeat aortic valve replacement has the potential of reduced operative insult (eg, reduced pain and length of hospital stay), which is attractive to patients, who must ultimately carry the morbidity and mortality burdens of repeat sternotomy. ${ }^{6,8}$ So why even consider repeat surgical aortic valve replacement? The short answer is because re-SAVR allows for a complete fix of the failed prosthesis and related issues.

First and foremost, re-SAVR can be done with low operative mortality. Outcomes from quaternary referral centers report similar operative mortality with re-SAVR compared with primary aortic valve replacement. Potter and colleagues ${ }^{5}$ previously reported an operative mortality of $4.9 \%$ in 162 patients operated with isolated re-SAVR, which was similar to the $3.1 \%$ rate in a contemporary group of 2290 patients who underwent primary aortic valve replacement $(P=.243)$. And in a more recent all-comers study of re-SAVR patients, including those who underwent a concomitant cardiac operation, Sedeek and colleagues ${ }^{6}$

From the Department of Cardiovascular Surgery, Mayo Clinic, Rochester, Minn. Received for publication Oct 11, 2020; revisions received Nov 17, 2020; accepted for publication Dec 21, 2020; available ahead of print Feb 4, 2021.

Address for reprints: Kevin L. Greason, MD, Department of Cardiovascular Surgery, Mayo Clinic, 200 First St, Rochester, MN 55905 (E-mail: greason.kevin@mayo. edu).

J Thorac Cardiovasc Surg 2022;163:940-3

$0022-5223 / \$ 36.00$

Copyright $(2) 2021$ by The American Association for Thoracic Surgery

https://doi.org/10.1016/j.jtcvs.2020.12.147

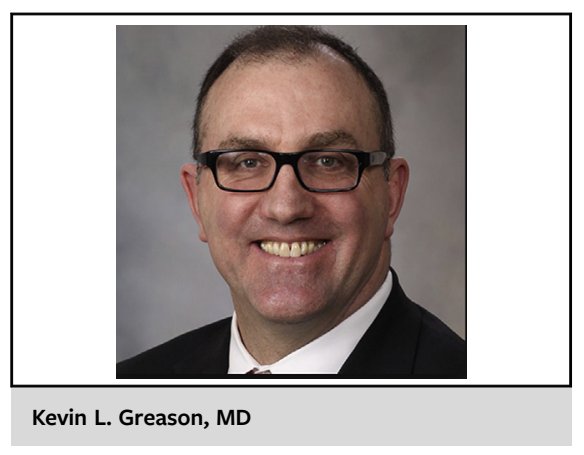

CENTRAL MESSAGE

Repeat surgical aortic valve replacement can be done with low and acceptable mortality risk. The operation allows for a complete fix of the failed prosthesis and related cardiac issues.

This Invited Expert Opinion provides a perspective on the following paper: Source article: J Am Coll Cardiol. 2020 Aug 4;76(5):489-499. doi.org/10.1016/j.jacc.2020.06.010

See Commentaries on pages 944 and 945.

reported operative death in only $3 \%$ of 260 patients. However, equipoise was not present in the Society of Thoracic Surgeons Adult Cardiac Database study published by Kaneko and colleagues, ${ }^{10}$ who reported an operative mortality rate of $5.4 \%$ in 3380 patients who underwent isolated reSAVR and $2.7 \%$ in 54,183 patients who underwent primary AVR $(P<.001) .{ }^{10}$ Possible reasons for the discrepant conclusions include lack of operator skill and/or greater power to show a statistical difference in the STS study, related to technical difficulty of a repeat operation, as well as a higher patient risk profile.

How does re-SAVR compare directly to VIV TAVR? Two large administration database comparisons of the respective procedures have been published recently. In the French administrative hospital-discharge database study, 30-day mortality was higher in propensity-matched patients who underwent re-SAVR compared with those who underwent VIV TAVR $(7.3 \%$ vs $3.6 \% ; P=.01) .{ }^{11}$ In a review of $\mathrm{Na}-$ tional Readmission Database claims, Hirji and colleagues ${ }^{12}$ also reported higher 30-day mortality in patients who 
underwent re-SAVR $(5.0 \%$ vs $2.8 \% ; P=.018)$. However, in a single institution study, Sedeek and colleagues ${ }^{6}$ compared re-SAVR $(\mathrm{n}=260)$ to VIV TAVR $(\mathrm{n}=90)$ and reported similar operative mortality in the groups $(3 \%$ vs $2 \% ; P=1.000)$ irrespective of the Society of Thoracic Surgeons Adult Cardiac Surgery operative mortality risk category. ${ }^{6}$ And from the Heart Centre Leipzig, Woitzeck and colleagues ${ }^{13}$ reported comparable mortality rates in 111 patients who underwent re-SAVR and 147 who underwent VIV TAVR $(4.1 \%$ vs $4.5 \% ; P=.87){ }^{13}$

These are the most recent operative mortality data. There are obvious limitations to these data and analyses. The majority of studies are not reflective of the real-world population of patients who present with a failed stented biological aortic prosthesis. Many of the studies excluded patients treated with concomitant cardiac operation. ${ }^{5,10-12}$ This is an important bias, given that roughly $30 \%$ of re-SAVR patients underwent a concomitant cardiac procedure in the all-comers studies. ${ }^{6,13}$ There are additional well-defined limitations of the administrative databases; for example, although both administrative database studies excluded concomitant cardiac procedures, they also lacked important echocardiography data, such as ejection fraction, ${ }^{11,12}$ and the National Readmission Database lacks data on patient risk score. ${ }^{12}$ It is difficult to make a direct comparison from the literature, but I believe it reasonable to say that re-SAVR can be done with acceptable operative mortality. Others agree. ${ }^{10}$

What about long-term mortality outcomes? VIV TAVR is a relatively recent technology with limited long-term outcome data. In the French registry, the operative and early mortality benefit of VIV TAVR was lost with longer followup (ie, median 516 days). ${ }^{11}$ The mortality curve of the VIV TAVR group crossed over that of the re-SAVR group at approximately 2 years, with longer follow-up showing a benefit for the re-SAVR group. This is demonstrated in the reported higher incidence rate ratio of long-term allcause death (1.14) with VIV TAVR compared with reSAVR. It is not surprising that there was also a significantly increased incidence rate ratio of repeat hospitalization in the VIV TAVR group (1.37). I doubt that these 2 findings are a coincidence. Sedeek and colleagues ${ }^{6}$ likewise reported a similar survival curve inversion after approximately 2 years, with further follow-up appearing to favor the reSAVR group. These are the best long-term comparison outcome data.

Why should time from operation favor the re-SAVR group? The answer is likely because there are consequences to placing a valve inside of a small valve. A diameter $<23 \mathrm{~mm}$ is the historical definition of a small prosthesis. ${ }^{14}$ Tam and colleagues ${ }^{15}$ published a review of aortic valve prosthesis size in 214,390 patients recorded between 2007 and 2016 in the Society of Thoracic Surgeons Adult Cardiac Surgery Database. It is disappointing to note that the implanted mean labeled valve size has actually decreased from before 2007 to after $2007(22.91 \pm 2.38$ vs $22.88 \pm 2.29 ; P=.012$ ). It seems that insertion of a small prosthesis is a common occurrence. This is corroborated by the Virginia Cardiac Surgery Quality Initiative group who in their review of 4621 patients found that almost $40 \%$ of patients received a small prosthesis. ${ }^{14}$ Prosthesis-patient mismatch is the unwanted outcome of VIV TAVR in a small aortic valve prosthesis.

There is a growing body of literature describing the negative influence of prosthesis-patient mismatch on outcomes after aortic valve replacement. Dahlbacka and colleagues ${ }^{16}$ reported a $46 \%$ incidence of prosthesis-patient mismatch in 4097 patients who underwent surgical aortic valve replacement in the FinnValve registry. Importantly, they observed significantly worse survival in patients with moderate and severe prosthesis-patient mismatch $(P=.001$, log-rank test). In a review of 62,125 patients in the Society of Thoracic Surgeons/American College of Cardiology Transcatheter Valve Therapy Registry, Herrmann and colleagues ${ }^{17}$ reported a prosthesis-patient mismatch in 22,785 patients $(37 \%)$, including 7514 patients with severe mismatch. ${ }^{17}$ The study reported an increased risk of death (hazard ratio [HR], 1.19) and heart failure-related hospitalization (HR, 1.12) associated with severe prosthesis-patient mismatch.

It seems that prosthesis-patient mismatch may be the norm following VIV TAVR. Our group reported severe prosthesis-patient mismatch in $44 \%$ of all VIV TAVR patients and in $66 \%$ of patients who received a $23-\mathrm{mm}$ or smaller VIV TAVR prosthesis. ${ }^{6}$ These rates were significantly higher than those reported in the re-SAVR group ( $12 \%$ and $17 \%$, respectively; $P<.001$ for both). The high rate of associated prosthesis-patient mismatch was also noted by Woitek and colleagues, ${ }^{13}$ who reported prosthesis-patient mismatch in $68 \%$ of patients following VIV TAVR, including severe mismatch in $25 \%$ of patients and moderate mismatch in $43 \%$. Again, these rates were significantly higher than those reported in the re-SAVR group $(9 \%$ and $14 \%$, respectively; $P<.001)$. Yes, there are percutaneous options to prevent mismatch, ${ }^{18}$ but poor valve hemodynamic function after VIV TAVR insertion has been consistently reported in the published literature. ${ }^{6,8,19}$

Re-SAVR has several advantages over VIV TAVR. First and foremost, it allows for implantation of a fully operational standard type valve. There is no potential for underexpansion of the valve and its attended negative influence on valve durability. ${ }^{20}$ The operation also allows the ability to enlarge the aortic valve annulus and even to offer a more 
durable mechanical valve prosthesis substitute, both of which were common occurrences in the study from Sedeek and colleagues (17\% and $39 \%$, respectively). ${ }^{6}$ Second, it allows for repair of concomitant cardiac problems, which can be important comorbidities in upward of $30 \%$ of patients with a failed stented biological prosthesis. ${ }^{6,13}$ What of coronary artery occlusion, aortic aneurysm formation, hypertrophic cardiomyopathy, atrial fibrillation, and associated mitral and tricuspid valve dysfunction? Yes, there are percutaneous options to address some of these comorbidities, ${ }^{21}$ but are the options of similar efficacy in the setting of important postoperative prosthesis-patient mismatch? I doubt it. Importantly, there are no comparison data.

It would be easy for me to join the call for a randomized-prospective study comparing re-SAVR and VIV TAVR, but is that really what we need? As of this date, the aortic valve prosthesis size is small in the majority of the aortic valve replacement population. ${ }^{15}$ Is it ethical to randomize these patients to a VIV TAVR, which is associated with a significantly higher prevalence of prosthesis-patient mismatch, compared with re-SAVR? Do we anticipate an alternative long-term outcome associated with severe prosthesis-patient mismatch in the future? Do we fracture every VIV TAVR valve to achieve the best hemodynamic outcome ${ }^{18}$ In my opinion, a randomized trial is not needed, not just yet; what we need is good surgery at the primary aortic valve replacement. This includes primarily the avoidance of prosthesispatient mismatch with aortic root enlargement. ${ }^{22,23}$ Furthermore, the long-term benefit of mechanical prostheses should be emphasized to the patient and cardiologist. ${ }^{24}$ Here is the take-home point: there is no zero-risk option for repeat aortic valve replacement.

Patient centeredness is the focus of health care and the cornerstone of informed consent. ${ }^{25}$ Given that the type of operation is ultimately the choice of the patient, I specifically discuss operative mortality, long-term mortality, prosthesis-patient mismatch, valve choice, and concomitant cardiac conditions when counseling patients with a failed biological aortic valve prosthesis about re-SAVR. The focus is patient-oriented benefits and procedurespecific risks, both qualitative and quantitative. ${ }^{26}$ This is the surgeon's due diligence. The patient is in control of the choice. Give them this information so that they can make the correct decision.

To paraphrase Mark Twain, I believe the reports of reSAVR's death have been greatly exaggerated.

\section{Conflict of Interest Statement}

The author reported no conflicts of interest.

The Journal policy requires editors and reviewers to disclose conflicts of interest and to decline handling or reviewing manuscripts for which they may have a conflict of interest. The editors and reviewers of this article have no conflicts of interest.

\section{References}

1. BrainyQuote. Mark Twain quotes. Available at: https://www.brainyquote.com/ quotes/mark_twain_141773. Accessed October 10, 2020.

2. Brown JM, O'Brien SM, Wu C, Sikora JA, Griffith BP, Gammie JS. Isolated aortic valve replacement in North America comprising 108,687 patients in 10 years: changes in risks, valve types, and outcomes in the Society of Thoracic Surgeons National Database. J Thorac Cardiovasc Surg. 2009;137:82-90.

3. Culler SD, Cohen DJ, Brown PP, Kugelmass AD, Reynolds MR, Ambrose K, et al. Trends in aortic valve replacement procedures between 2009 and 2015: has transcatheter aortic valve replacement made a difference? Ann Thorac Surg. 2018;105:1137-43

4. Jamieson WR, Burr LH, Miyagishima RT, Janusz MT, Fradet GJ, Ling H, et al. Re-operation for bioprosthetic aortic structural failure-risk assessment. Eur J Cardiothorac Surg. 2003;24:873-8.

5. Potter DD, Sundt TM III, Zehr KJ, Dearani JA, Daly RC, Mullany CJ, et al. Operative risk of reoperative aortic valve replacement. J Thorac Cardiovasc Surg. 2005;129:94-103.

6. Sedeek AF, Greason KL, Sandhu GS, Dearani JA, Holmes DR Jr, Schaff HV. Transcatheter valve-in-valve vs surgical replacement of failing stented aortic biological valves. Ann Thorac Surg. 2019;108:424-30.

7. Wenaweser P, Buellesfeld L, Gerckens U, Grube E. Percutaneous aortic valve replacement for severe aortic regurgitation in degenerated bioprosthesis: the first valve-in-valve procedure using the CoreValve revalving system. Catheter Cardiovasc Interv. 2007;70:760-4.

8. Dvir D, Webb JG, Bleiziffer S, Pasic M, Waksman R, Kodali S, et al. Transcatheter aortic valve implantation in failed bioprosthetic surgical valves. JAMA. 2014;312:162-70

9. American College of Cardiology. FDA expands approval for valve-in-valve replacement. 2015. Available at: https://www.acc.org/latest-in-cardiology/ articles/2015/03/31/14/14/fda-expands-approval-for-valve-in-valve-replacement. Accessed November 17, 2020.

10. Kaneko T, Vassileva CM, Englum B, Kim S, Yammine M, Brennan M, et al. Contemporary outcomes of repeat aortic valve replacement: a benchmark for transcatheter valve-in-valve procedures. Ann Thorac Surg. 2015;100:1298-304.

11. Deharo P, Bisson A, Herbert J, Lacour T, Saint Etienne C, Porto A, et al. Transcatheter valve-in-valve aortic valve replacement as an alternative to surgical re-replacement. J Am Coll Cardiol. 2020;76:489-99.

12. Hirji SA, Percy ED, Zodd CK, Malarczyk A, Harloff MT, Yazdchi F, et al. Comparison of in-hospital outcomes and readmissions for valve-in-valve transcatheter aortic valve replacement vs reoperative surgical aortic valve replacement: a contemporary assessment of real-world outcomes. Eur Heart J. 2020;41: 2747-55.

13. Woitek FJ, Stachel G, Kiefer P, Haussig S, Leontyev S, Schlotter F, et al. Treatment of failed aortic bioprostheses: an evaluation of conventional redo surgery and transfemoral transcatheter aortic valve-in-valve implantation. Int J Cardiol. 2020;300:80-6.

14. LaPar DJ, Ailawadi G, Bhamidipati CM, Stukenborg G, Crosby IK, Kern JA, et al. Small prosthesis size in aortic valve replacement does not affect mortality Ann Thorac Surg. 2011;92:880-8.

15. Tam DY, Rocha RV, Wijeysundera HC, Austin PC, Dvir D, Fremes SE. Surgical valve selection in the era of transcatheter aortic valve replacement in the Society of Thoracic Surgeons database. J Thorac Cardiovasc Surg. 2020;159: 416-27.e8.

16. Dahlbacka S, Laakso T, Kinnunen E-M, Moriyama N, Laine M, Virtanen M, et al. Patient-prosthesis mismatch worsens long-term survival: insights from the FinnValve registry. Ann Thorac Surg. 2021;111:1284-90.

17. Herrmann HC, Daneshvar SA, Fonarow GC, Stebbins A, Vemulapalli S, Desai ND, et al. Prosthesis-patient mismatch in patients undergoing transcatheter aortic valve replacement: from the STS/ACC TVT registry. $J$ Am Coll Cardiol. 2018;72:2701-11.

18. Allen KB, Chhatriwalla AK, Saxon JT, Cohen DJ, Nguyen TC, Webb J, et al. Bioprosthetic valve fracture: technical insights form a multicenter study. J Thorac Cardiovasc Surg. 2019;158:1317-28.e1.

19. Condradi L, Silaschi M, Seiffert M, Lubos E, Blankenberg S, Reichenspurner H, et al. Transcatheter valve-in-valve therapy using 6 different devices in 4 anatomic positions: clinical outcomes and technical considerations. J Thorac Cardiovasc Surg. 2015;150:1557-65. 
20. Martin C, Sun W. Transcatheter valve underexpansion limits leaflet durability: implications for valve-in-valve procedures. Ann Biomed Eng. 2017;45:394-404.

21. Khan JM, Greenbaum AB, Babaliaros VC, Rogers T, Eng MH, Panone G, et al. The BASILICA trial: prospective multicenter investigation of intentional leaflet laceration to prevent TAVR coronary obstruction. JACC Cardiovasc Interv. 2019; $12: 1240-52$.

22. Penaranda JG, Greason KL, Pislaru SV, Schaff HV, Daly RC, Park SJ, et al. Aortic root enlargement in octogenarian patients results in less patientprosthesis mismatch. Ann Thorac Surg. 2014;97:1533-8.

23. Haunschild J, Scharnowski S, Mende M, von Aspern K, Misfeld M, Mohr FW, et al. Aortic root enlargement to mitigate patient-prosthesis mismatch: do early adverse events justify reluctance? Eur J Cardiothorac Surg. February 20, 2019 [Epub ahead of print].

24. Diaz R, Hernandez-Vaquero D, Alvarez-Cabo R, Avanzas P, Silva J, Moris C, et al. Long-term outcomes of mechanical versus biological aortic valve pros- thesis: systemic review and meta-analysis. J Thorac Cardiovasc Surg. 2019 158:706-14.e18.

25. Krumholz HM. Informed consent to promote patient-centered care. JAMA. 2010; 303:1190-1.

26. Spatz ES, Bao H, Herrin J, Desai V, Ramanan S, Lines L, et al. Quality of informed consent documents among US hospitals: a cross-sectional study. BMJ Open. 2020;19:e033299.

Key Words: aortic valve replacement, repeat surgical aortic valve replacement, transcatheter aortic valve-in-valve insertion, transcatheter aortic valve-in-valve replacement, biological prosthesis, structural valve deterioration, valve failure 